Demiryolu Mühendisliği

Temmuz 2021

Sayı:14, Sayfa: $143-153$

Araştırma Makalesi

http://dergipark.org

e-ISSN: 2687-2463, ISSN: 2149-1607

Railway Engineering

July 2021

Issue:14, Page: 143-153

Research Article

\title{
Akıllı Raylı Sistemlerde Kullanılan Alt Sistemlerin Kritik Seviye Analizi
}

\author{
Cevat ÖZARPA*1(D), İsa AVCI ${ }^{2}$, Bahadır Furkan KINACI $^{3}$ (D) \\ ${ }^{1}$ Karabük Üniversitesi, Mühendislik Fakültesi, Makine Mühendisliği, Karabük, Türkiye \\ ${ }^{2}$ Karabük Üniversitesi, Mühendislik Fakültesi, Bilgisayar Mühendisliği, Karabük, Türkiye \\ ${ }^{3}$ Karabük Üniversitesi, Mühendislik Fakültesi, Raylı Sistemler Mühendisliği, Karabük, Türkiye \\ *cevatozarpa@karabuk.edu.tr
}

(Alınıs/Received: 14.05.2021, Kabul/Accepted: 23.06.2021, Yayımlama/Published: 31.07.2021)

Öz: Ulaşımda raylı sistemlerin kullanımı, insanlar ve toplum üzerinde önemli ekonomik ve sosyal bir yere sahiptir. İnsan hayatı üzerinde etkisi olan diğer tüm sistemler gibi, raylı ulaşım sistemlerinin etkili bir biçimde kullanılabilmesi yeterli, güvenli adaptasyon ve emniyet ile sağlanmaktadır. Dijitalleşmeye imkân bulan tüm alanlar gibi, raylı ulaşım sistemleri de akıllı sistemlerin kullanıma imkân bulmakta ve gelişimini hızla sürdürmektedir. Raylı sistemlerde istasyonlar, demiryolu hatları, araç üstü ekipmanları ve merkezi yönetim sistemleri uygulama alanı bulan yapılar içerisindedir. Bu çalışmada akıllı raylı sistemlerde kullanılan kritik alt sistemler AHP yöntemi ile önceliklendirme seviyeleri hesaplanarak kritiklik analizleri yapılmıştır. Analizler yapılırken, 5 ayrı uzman görüşü alınmış derecelendirmeler uzmanların ortalama değerleri olacak şekilde ortaya konulmuştur. Yapılan kritiklik analizlerine göre riskler seviyelendirilmiş sistemsel olarak önemli yapılar ifade edilmiştir. Yapılan hesaplamalara göre, önem öncelikleri \%26,65 ile sinyalizasyon sistemleri, \%23,47 ile makas sistemleri olarak ortaya çıkmaktadır. Dijital gelişmeler ışığında akıllı raylı sistemlerin siber güvenlik açılarına ve saldırılarına maruz kalabileceği ön görülmüştür. Bu tehditler sonucu sistemlerde siber güvenlik açısından gerekli çalışmaların yapılmasını zorunlu hale getirmiştir.

Anahtar kelimeler: Akıllı raylı sistemler, Dijitalleşme, Risk analizi, Analitik hiyerarşik süreci (AHP)

\section{Critical Level Analysis of Subsystems in Smart Rail Systems}

\begin{abstract}
The use of rail systems in transportation has an important and social place on people and society. Availability in a widely used region is available in all systems around the world, with usability on a widespread human. All areas that find it oriented towards digitalization, rail training systems are also smart training applications exercises. Stations, system management systems, onboard equipment, and central systems are systems that find application in rail systems. In this study, critical subsystems used in smart rail systems were analyzed and calculated using the AHP method, and criticality was made. While the analyzes are being made, they will be from 5 different environments that will be reviewed in detail. According to the criticality analysis, risks are leveled and systemically important structures. According to the calculations, priority priorities emerge as signaling systems with $26.65 \%$ and systems with $23.47 \%$ difference. It is reflected from the front that smart rail systems can be exposed to cybersecurity vulnerabilities through digital means. These threats are preparations to improve cybersecurity systems in systems.
\end{abstract}

Keywords: Intelligent rail systems, Digitalization, Risk analysis, Analytic hierarchy process (AHP)

\section{Giriş}

Teknolojide yaşanan gelişmeler ile birlikte haberleşme, ulaşım, kontrol ve güvenlik sistemlerinde dijitalleşme önemli bir artış göstermiştir. Raylı sistemlerde kullanılan her türlü kontrol, bakım, konfor ve güvenlik sistemleri uluslararası normlara göre düzenlenip ve gelişip belirli fiziksel veya sanal bağlantılı alt yapılar sayesinde birbirleri ile etkileşim halinde bulunmaktadır [1], [2]. Raylı sistemler sektöründe mevcut alt yapılarda yaşanan dijitalleşme gelişimi yanı sıra yeni hat ve 
lokasyon artışı ile yenilikçi yaklaşıma sahip dijital teknolojilerin kullanımında artış görülmektedir [3], [4].

Mevcut alt yapı ve gelişmeler incelendiğinde, ülkemizde, 2009 öncesi YHT hattı bulunmazken bugün yaklaşık $1.213 \mathrm{~km}$ uzunluğa ve toplam raylı sistem alt yapı uzunluğu ise $12.740 \mathrm{~km}$ uzunluğa ulaşmıştır. TCDD 2020 Yılı Performans Programı, Lojistik ve Ulaştırma sektörü öngörüsüne göre 2023 yılı itibari ile YHT hat uzunluğunun $5.595 \mathrm{~km}$ olması hedeflenmektedir [5], [6]. Ülkemizdeki raylı sistem gelişimine ilave olarak dünya üzerinde yük ve yolcu taşımacılığ için kullanılan ve en güvenli taşıma metotlarından olan raylı sistem taşımacılığının, uluslararası Railway Delivery Group verilerine göre 2040 yılına kadar \%40 oranında artış göstereceği öngörülmektedir [7]. Oluşan bu gelişmeler, dijital teknolojilerin gelişimine ayak uydurmak ve bu teknoloji ile ortaya çıkan güvenlik risklerinin ortadan kaldırılabilmesi için akademik ve sektör odaklı çalışmalara ihtiyaç duymaktadır. Ortaya çıkan ihtiyaçlar 1şı̆̆ında dünyadaki sektör temsilcisi firmalar çeşitli çalışmaları yaparken ülkemizde raylı ulaşım sektöründe en önemli firması olan Türkiye Cumhuriyeti Devlet Demiryolları (TCDD) firması gerekli çalışmalar için alt yap1 organizasyonuna başlamıştır. TCDD strateji ve geliştirmelerinde, veri sistemlerinin entegrasyonu ve dijital sistemlerinin taşıma sektörüne dahil edilmesi ile ilgili gerekli birçok çalışmayı hayata geçirmeye başladığı TCDD resmi kaynak ve raporlarında gözlemlenmektedir. TCDD'nin iştirak kurumlarından olan TÜRASAŞ firması Eskişehir Bölge Müdürlüğü Dijital Dönüşüm Ofisi bünyesinde yapılan çalışmada, Endüstri 4.0 uygulamalarından her türlü dijital teknolojilerin uygulanmasına kadar dijitalleşme alt yapısını oluşturulmaya başlanmış olup test istasyonu haline dönüşmesi sağlanmıştır [8]. Yapılan bu ve benzeri çalışmalar ile ülkemizde raylı sistemler içerisindeki akıllı ulaşım alt yapısı gelişmesinin sağlanması hedeflenmektedir [9].

AHP yöntemi kullanılarak yapılan çalışmalarda çeşitli risk değerlendirmeleri yapılmıştır. Özdemir vd. tarafından yapılan demiryolu çalışmaları ile ilgili bir çalışmada demiryolu araçlarının bakım planlaması AHP metoduda kullanılarak yapılmış ve bakıma gönderilecek ekipmanlar ile ilgili önceliklendirmeler gerçekleştirilmiştir [10]. Mohajeri vd. tarafindan yapılan bir diğer çalışmada ise istasyon yer seçimi gerçekleştirilirken AHP metodu kullanılmıştır [11]. Bıyıkçı tarafindan yapılan yüksek lisans tezinde ve Avcı tarafindan yapılan doktora tezinde yapılan çalışmalarda doğalgaz akı1lı şebekesi için olgunluk ve risk seviyelendirmesi AHP metodu ile gerçekleştirilmiştir [12], [13]. Ayrıca Kaya tarafından yapılan yükssek lisans tez çalışmasında önceden önlem alınıp izlenmeyen veya risk analizleri yapılmayan demiryolu sistemlerinde daha büyük sorunların ortaya çıkabileceği öngörülmüştür [14].

Raylı ulaşım sistemlerinde akıllı ulaşım sistemlerinin kullanılması, işletme ve sistem güvenlik kolaylıklarını sağlamakta ve bu sayede kazalar önlenmeye çalışılmaktadır. Ancak akıllı ulaşım sistemleri üzerinde oluşabilecek sistemsel arıza, hata veya siber saldırılar durumunda kazalar meydana gelmektedir [15], [16], [17] . Bu alanda yapılan incelemelerde, son 15 yılda ülkemizde 200'e yakın insanın başta sinyalizasyon sistemleri hataları olmak üzere farklı sebeplerden kazalarda hayatlarını kaybettiği gözlemlenmiştir. Yaptığımız çalışmada, akıllı raylı sistemlerin temel alt yapı mimarisi ve haberleşme sistemleri ile birlikte bu sistemler üzerinde çalışan kritik alt sistemler Analitik Hiyerarşik Süreci (AHP) metodu ile risk analizleri yapılacaktır. Bu çalışmada AHP yöntemi ile risk analizi sonucunda kritik alt sistemlerin önem dereceleri belirlenecek ve sistemsel olarak detaylı incelemelerin yapılması gereken başlıklar ele alınacaktır [18].

\subsection{Akullı raylı ulaşım sistemleri}

Dijital teknolojiler ile akıllı ulaşım ve raylı sistemlerdeki gelişmeler taşıtların ve istasyonların her türlü kontrol edilebilir sistemlerini fiziksel ve sanal bağlantı ile kontrol edilmelerine imkân tanımıştır. Bu sistemlerin belirli merkezlerden kontrolleri, oluşabilecek kaza, arıza, veri kaybı, vakit ve gelir kaybı gibi konulardan korunmasına ve elden edilen tecrübe ile daha uygun verimli 
yeni tasarım ve yapıların oluşumuna katkıda bulunmaktadır. Kent içi ile şehirler arası yük ve yolcu taşınması demiryolu sistemleri ile yapılırken birçok farklı sistem kontrol merkezleri ile takip edilmektedir. Siklıkla yapılan uygulamalarda bir ana kontrol merkezinden alt kontrol merkezleri olan istasyon kontrol merkezleri ve hat üzerindeki taşıt ve yol sistemleri (hat güvenlik sistemleri, makas ve sinyalizasyon sistemleri gibi) farklı LAN, F/O, GPRS gibi haberleşme alt yapıları ile kontrol edilmektedir. Uygulamalarda, ana kontrol merkezinden kontrol edilen istasyon kontrol sistemleri ve yol sistemleri, yapının durumu ve hat boyutu ile farklılık göstermektedir [19], [20], [21]. Şekil 1' de ana kontrol merkezinden kontrol edilen alt istasyon kontrol merkezleri ve taşıt kontrolleri ağ mimarisi gösterilmiştir.

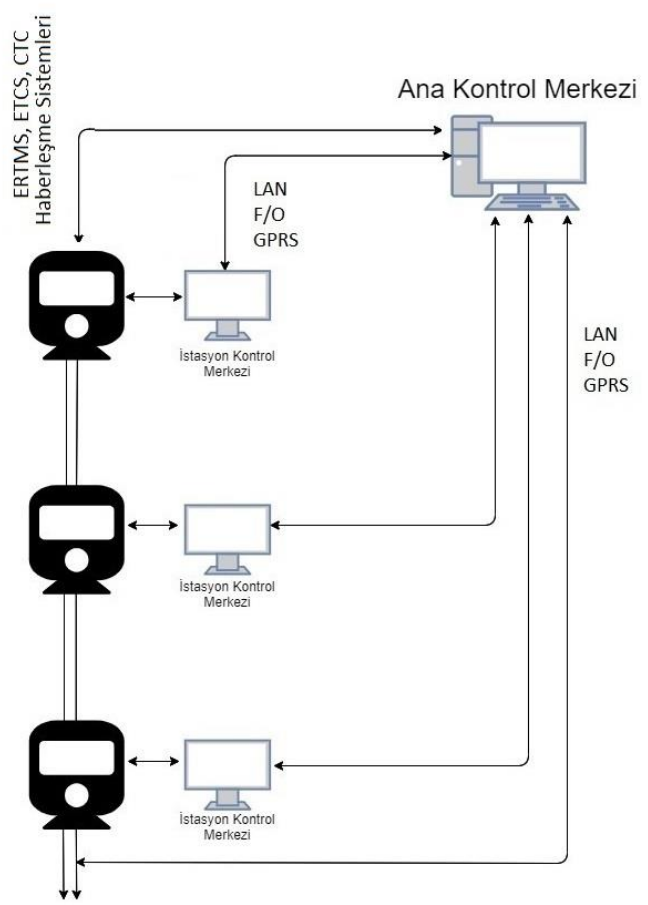

Şekil 1. Akıllı raylı sistemlerde ana kontrol ağ mimarisi

Geliştirilen yapılarda ana kontrol merkezi ile haberleşen istasyon kontrol sistemleri taşıt seyri, güvenlik, kontrol ve konfor sistemlerinin kontrollerini sağlamaktadır. İstasyon içerisinde bulunan kontrol, güvenlik ve konfor sistemlerinden olan 1şıklandırma, merdiven, havalandırma, kamera, asansör, bilet kontrol ve güvenlik sistemleri kontrol edilmektedir. İstasyon haricinde taşıt hareket, güvenlik, konfor ve kontrol sistemleri ile birlikte makas, sinyal ve yol kontrol sistemleri kontrol edilmektedir [22], [23]. Şekil 2'de ana kontrol merkezi ile haberleşen istasyon kontrol sistemlerinin istasyon içerisinde ve haricinde kontrol etmiş olduğu sistemlerin yapısı gösterilmiştir. 


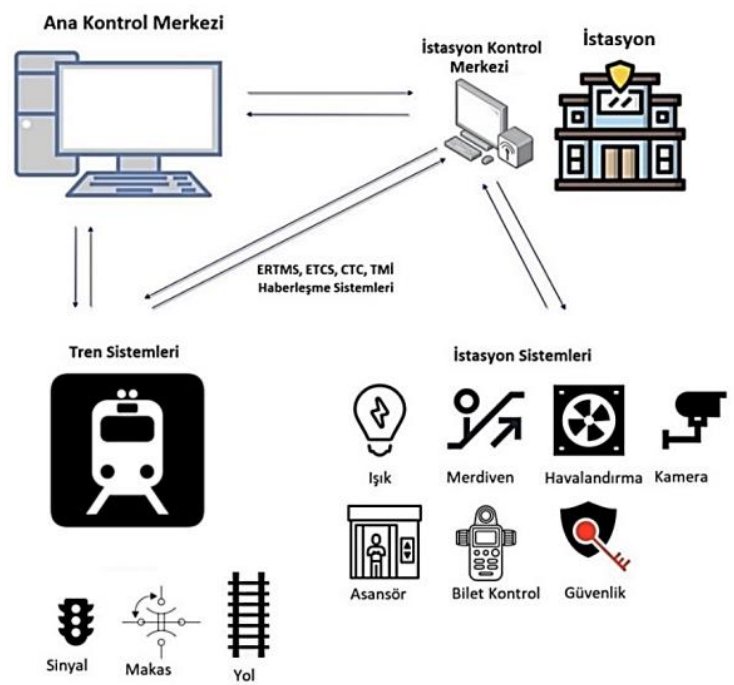

Şekil 2. Akıllı raylı sistemlerde istasyon kontrol merkezlerinin kontrol ettiği sistemler

Ana kontrol ve istasyon kontrol merkezlerinden kontrol edilen raylı sistem taşıtları üzerinde her türlü konfor, seyir, kontrol sistemleri kontrol edilebilmektedir. Bu sistemler tüm yolcu sistemlerin kontrol ederken ilave olarak seyir esnasında merkezle haberleșerek gerekli seyir planlanması ve hareket işlemlerinide yerine getirmektedir. Şekil 3' de raylı sistem taşıtı üzerinde kontrol edilebilen sistemler gösterilmiştir.

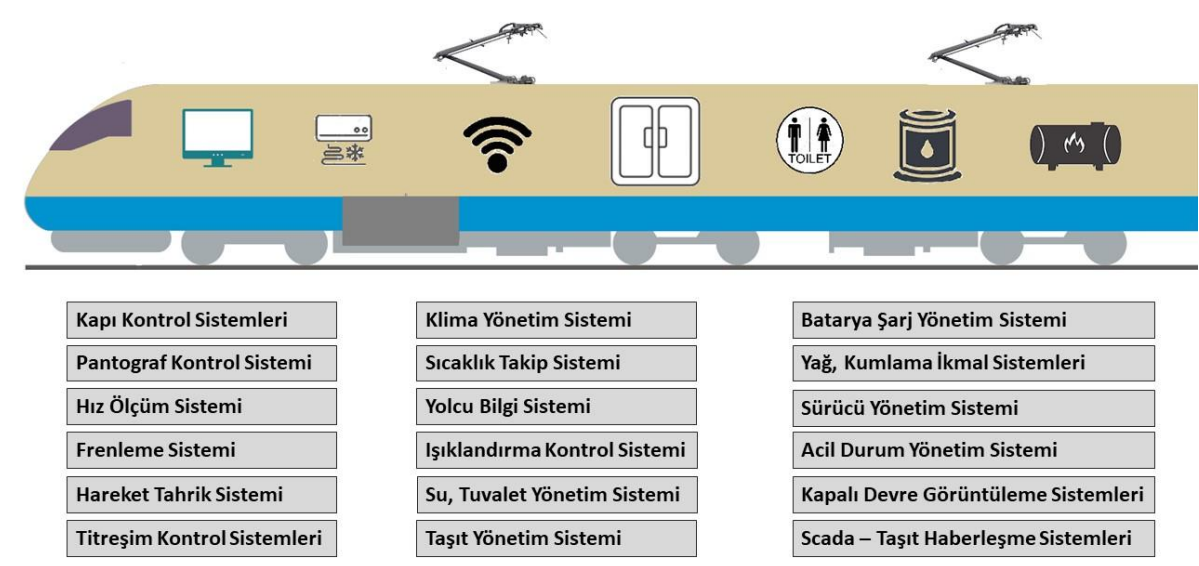

Şekil 3. Akıllı raylı sistemlerde taşıt üzerinde kontrol edilebilen sistemler

\subsection{Akıllı raylı sistemlerde kullanılan alt sistemler}

Raylı ulaşım işletmeciliği yapılırken seyir, taşıt, istasyon, yolcu ve personellerin güvenliklerinin sağlanması ve çeşitli konfor ve kolaylık sistemlerinin sorunsuz olarak işletilebilir durumda olması gereklidir [24]. Raylı ulaşım sisteminde var olan alt sistemler teknoloji gelişimi ve dijitalleşmenin yaygınlaşması ve akı1lı ulaşım sistemlerin entegrasyonu ile akıllı raylı sistemlerin oluşumunu sağlamıştır. Akıllı raylı sistem uygulamalarında kritik önemde olan başlıca alt sistemler seyir kontrol sistemleri, güvenlik kontrol sistemleri, ikmal, muayene ve sistemsel yönetim sistemleri ile konfor ve kolaylık sistemlerinden meydana gelmektedir. Tablo 1'de ak1ll raylı sistemlerden kullanılan alt sistemlerin detayları verilmiştir [25], [26]. 
Tablo 1. Akıllı raylı sistemlerde kullanılan alt sistemler

\begin{tabular}{|c|c|}
\hline Alt Sistem & Kapsadığg Detay \\
\hline Sinyalizasyon Sistemleri & $\begin{array}{l}\text { Tüm seyir, makas, sinyal ve hemzemin geçitlerin } \\
\text { kontrol edildiği sistemler }\end{array}$ \\
\hline Makas Sistemleri & Demir yolu hattı üzerinde yön tayini sağlayan sistemler \\
\hline Tren Teşkil ve İkmal Sistemleri & $\begin{array}{l}\text { Yakıt, kum vb. ikmallerin, seyir öncesi fren kontrolleri } \\
\text { gibi kontrollerin yapıldığı sitemler }\end{array}$ \\
\hline $\begin{array}{l}\text { ERTMS, CTC ve TMİ Haberleşme } \\
\text { Sistemleri }\end{array}$ & $\begin{array}{l}\text { Trenlerin merkezden sinyaller ve telefon ile } \\
\text { kontrollerinin saŏ }{ }_{\text {land }} \breve{g ̆}_{1} \text { sistemler }\end{array}$ \\
\hline $\begin{array}{l}\text { Tren Üzeri Konfor ve Kolaylık } \\
\text { Sistemleri }\end{array}$ & $\begin{array}{c}\text { Taşıt içerisinde iklimlendirme, 1şıklandırma, } \\
\text { bilgilendirme vb. sistemler }\end{array}$ \\
\hline $\begin{array}{c}\text { Tren Üzeri Dijital Bakım ve Kontrol } \\
\text { Sistemleri }\end{array}$ & $\begin{array}{l}\text { Tren üzeri gerekli sistemsel verilerin kontrol edildiği } \\
\text { (sıcaklık, basınç vb.) sistemler }\end{array}$ \\
\hline Sürücü Kontrol Sistemleri & Makinist bilgi ekranı ve kontrol sistemleri \\
\hline İstasyon Güvenlik ve Bilet Sistemleri & İstasyon içerisi güvenlik ve bilet satış sistemleri \\
\hline İstasyon İklimlendirme Sistemleri & İstasyon içerisi havalandırma ve klima sistemleri \\
\hline İstasyon Peron Kontrol Sistemleri & $\begin{array}{l}\text { İstasyon içerisi peron yönlendirme, kontrol ve güvenlik } \\
\text { sistemleri }\end{array}$ \\
\hline
\end{tabular}

\section{Metot}

Yapılan bu çalışmada, demiryolu taşımacılığında dijital alt yapıya sahip sistemlerin detayları ve bu sistemlerde oluşabilecek arızalar sonucu karşılaşllacak olumsuzluklar ve riskler analitik hiyerarşi süreci kullanılarak önceliklendirilmiştir.

\subsection{Analitik hiyerarşi süreci (AHP)}

Analitik Hiyerarşi Süreci (AHP), ilk olarak Myers ve Alpert ikilisi tarafından 1968 yılında ortaya atılmış ve 1977 de ise Saaty tarafindan bir model olarak geliştirmiştir. Bu gelişmeler sayesinde karar verme problemlerinin çözümünde kullanılabilir hale getirilmiştir. Analitik hiyerarşi süreci, hiyerarşisinin tanımlanması sonrasında kullanılan, değişkenleri etkileyen faktörler açısından değişken noktaların yüzde dağılımlarını veren bir tahminleme ve karar verme yöntemi olarak açıklanabilir [27]. Analitik hiyerarşi süreci, bir hiyerarşisi üzerinde, önceden tanımlanmış bir karşılaştırma skalası kullanılarak kararı etkileyen faktörleri ve bu faktörler açısından karar noktalarının önem değerlerini karşılaştırmaktadır. Süreç sonrasında, karar parametreleri üzerinde yüzde dağılıma dönüştürmektedir. Değişken faktörler arası karşılaştırma matrisi, nxn boyutlu bir kare matristir. Örnek bir matrisi yapısı aşağıda gösterilmiştir [28], [29], [30].

$$
A=\left[\begin{array}{cccc}
a_{11} & a_{12} & \ldots & a_{1 n} \\
a_{21} & a_{22} & \ldots & a_{2 n} \\
\cdot & & & \cdot \\
\cdot & & & \cdot \\
\cdot & & & \cdot \\
a_{n 1} & a_{n 2} & \ldots & a_{n n}
\end{array}\right]
$$

Yapılan karşılaştırmalar, matrisinin tüm değerleri 1 olan köşegenin üst bölgesinde kalan değerler için yapılır. Köşegenin alt bölgesinde kalan bileşenler için ise doğal olarak (2) formülünü kullanmaktadır. 


$$
a_{j i}=\frac{1}{a_{i j}}
$$

Uygulanan formüllere göre, matrisinin birinci satır üçüncü sütun bileşeni $(i=1, j=3) 2$ değerini alıyorsa, karşılaştırma matrisinin üçüncü satır birinci sütun bileşeni $(i=3, j=1),(2)$ formülünden $1 / 2$ değerini alacaktır.

Tablo 2. AHP önem skalası

\begin{tabular}{cc}
\hline Önem Değerleri & Değer Tanımları \\
\hline 1 & Her iki faktörün eşit öneme sahip olması durumu \\
3 & 1. Faktörün 2. faktörden daha önemli olması durumu \\
5 & 1. Faktörün 2. faktörden çok önemli olması durumu \\
7 & 1. Faktörün 2. faktöre nazaran çok güçlü bir öneme sahip olması durumu \\
9 & 1. Faktörün 2. faktöre nazaran mutlak üstün bir öneme sahip olması durumu \\
$2,4,6,8$ & Ara değerler \\
\hline
\end{tabular}

Yüzde önem dağılımları belirlenirken, karşılaştırma matrisinin faktörler üzerinde birbirlerine göre önem seviyelerini belirli bir mantık boyuntunda gösterilir. Bu faktörlerin bütün içerisindeki ağırlıkları olan yüzde önem dağılımlarını belirlemek için, karşılaştırma matrisini oluşturan sütun vektörlerinden yararlanılır ve $n$ adet ve $n$ bileşenli B sütun vektörü oluşturulur. Formül (3) de vektör gösterilmiştir:

$$
B_{i}=\left[\begin{array}{c}
b_{11} \\
b_{21} \\
\cdot \\
\cdot \\
\cdot \\
b_{n 1}
\end{array}\right]
$$

B sütun vektörlerü hesaplanırken (4) formülü kullanılır.

$$
b_{i j}=\frac{a_{i j}}{\sum_{i=1}^{n} a_{i j}}
$$

\section{Akılı Raylı Sistemlerde Alt Sistem Kritik Önem Değerlendirilmesi ve Risk Analizi}

Akıllı raylı sistemlerdeki alt sistemler detaylı olarak incelendiğinde tüm bu sistemler kritik ve hayati öneme sahiptir. Riskler açısından ele alındığında her bir sistem kendi özelinde risk seviyesi bulunmaktadır. Akıllı raylı sistem işletmeciliğinde, haberleşme ve kontrol alt yapısı içerisinde yer alan alt sistemlerde 5 farklı uzman görüşü alınarak gerçekleştirilen Analitik Hiyerarşi Süreci uygulaması tablo 3' te gösterilmiştir. 
Tablo 3. Akıllı raylı sistemlerde alt sistem risk anahtar performans göstergeleri

\begin{tabular}{|c|c|c|c|c|c|c|c|c|c|c|}
\hline $\begin{array}{c}\text { Akıllı Raylı Sistemler } \\
\text { KPIs }\end{array}$ & 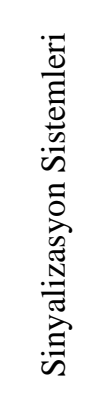 & 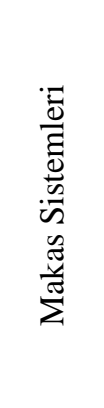 & 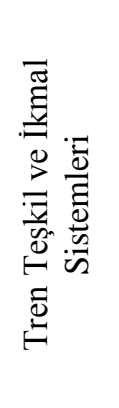 & 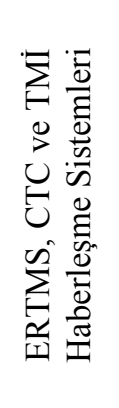 & 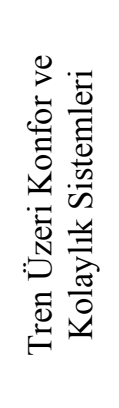 & 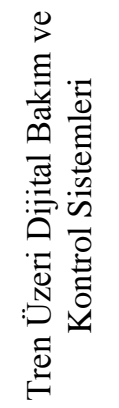 & 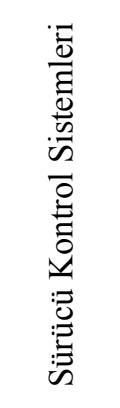 & 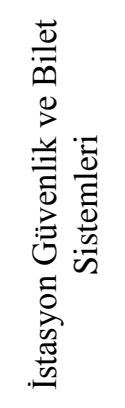 & 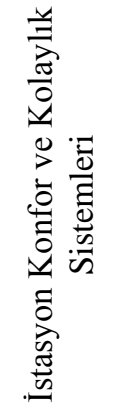 & 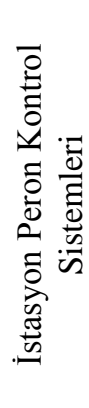 \\
\hline $\begin{array}{l}\text { Sinyalizasyon } \\
\text { Sistemleri }\end{array}$ & 1 & 5 & 3 & 5 & 5 & 9 & 9 & 3 & 9 & 9 \\
\hline Makas Sistemleri & 0,200 & 1 & 5 & 7 & 9 & 9 & 9 & 7 & 9 & 9 \\
\hline $\begin{array}{l}\text { Tren Teşkil ve İkmal } \\
\text { Sistemleri }\end{array}$ & 0,333 & 0,200 & 1 & 3 & 7 & 7 & 6 & 9 & 9 & 7 \\
\hline $\begin{array}{l}\text { ERTMS, CTC ve TMI } \\
\text { Haberleşme Sistemleri }\end{array}$ & 0,2 & 0,143 & 0,333 & 1 & 9 & 7 & 6 & 9 & 9 & 7 \\
\hline $\begin{array}{l}\text { Tren Üzeri Konfor ve } \\
\text { Kolaylık Sistemleri }\end{array}$ & 0,2 & 0,111 & 0,143 & 0,111 & 1 & 6 & 6 & 2 & 1 & 6 \\
\hline $\begin{array}{l}\text { Tren Üzeri Dijital } \\
\text { Bakım ve Kontrol } \\
\text { Sistemleri }\end{array}$ & 0,111 & 0,111 & 0,143 & 0,143 & 0,167 & 1 & 4 & 1 & 5 & 3 \\
\hline $\begin{array}{l}\text { Sürücü Kontrol } \\
\text { Sistemleri }\end{array}$ & 0,111 & 0,111 & 0,167 & 0,167 & 0,167 & 0,250 & 1 & 5 & 7 & 3 \\
\hline $\begin{array}{l}\text { İstasyon Güvenlik ve } \\
\text { Bilet Sistemleri }\end{array}$ & 0,333 & 0,143 & 0,111 & 0,111 & 0,500 & 1,000 & 0,200 & 1 & 7 & 3 \\
\hline $\begin{array}{l}\text { İstasyon Konfor ve } \\
\text { Kolaylık Sistemleri }\end{array}$ & 0,111 & 0,111 & 0,111 & 0,111 & 1,000 & 0,200 & 0,143 & 0,143 & 1 & 6 \\
\hline $\begin{array}{l}\text { İstasyon Peron Kontrol } \\
\text { Sistemleri }\end{array}$ & 0,111 & 0,111 & 0,143 & 0,143 & 0,167 & 0,333 & 0,333 & 0,048 & 0,167 & 1 \\
\hline Toplam & 2,711 & 7,041 & 10,151 & 16,786 & 33,000 & 40,783 & 41,676 & 37,190 & 57,167 & 54 \\
\hline
\end{tabular}

Yapılan uygulama sonucu alınan ortalama değerlere göre oluşan önem ağırlık sırası Tablo 4'te gösterilmiştir. Önem ağılık derecelendirilmesinin yaklaşık \% 50 lik kısmını siyalizasyon ve makas sistemleri oluşturmuştur.

Tablo 4. Akıllı raylı sistemlerde alt sistem risk anahtar performans göstergeleri önem ağırlık sırası

\begin{tabular}{|c|c|c|c|c|c|c|c|c|c|c|c|c|}
\hline $\begin{array}{c}\text { Ak1llı Raylı } \\
\text { Sistemler KPIs }\end{array}$ & 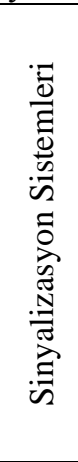 & 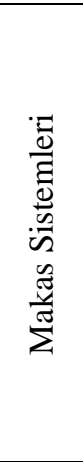 & 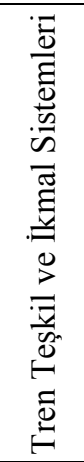 & 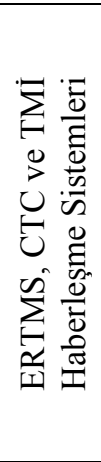 & 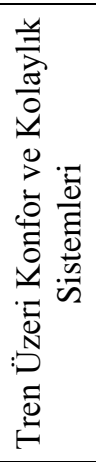 & 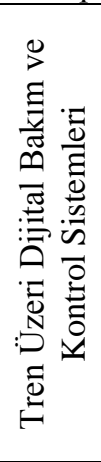 & 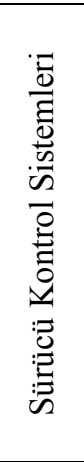 & 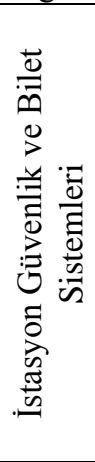 & 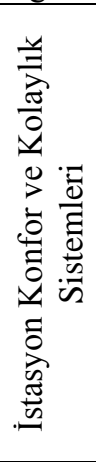 & 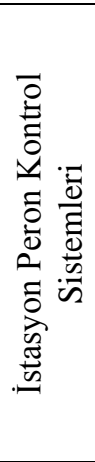 & 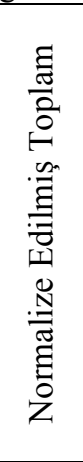 & 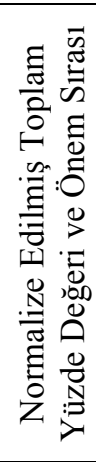 \\
\hline $\begin{array}{l}\text { Sinyalizasyon } \\
\text { Sistemleri }\end{array}$ & 0,37 & 0,71 & 0,30 & 0,30 & 0,15 & 0,22 & 0,22 & 0,08 & 0,16 & 0,17 & 2,67 & 26,65 \\
\hline
\end{tabular}




\begin{tabular}{|c|c|c|c|c|c|c|c|c|c|c|c|c|}
\hline Makas Sistemleri & 0,07 & 0,14 & 0,49 & 0,42 & 0,27 & 0,22 & 0,22 & 0,19 & 0,16 & 0,17 & 2,35 & 23,47 \\
\hline $\begin{array}{l}\text { Tren Teşkil ve } \\
\text { İkmal Sistemleri }\end{array}$ & 0,12 & 0,03 & 0,10 & 0,18 & 0,21 & 0,17 & 0,14 & 0,24 & 0,16 & 0,13 & 1,49 & 14,85 \\
\hline $\begin{array}{l}\text { ERTMS, CTC ve } \\
\text { TMİ Haberleşme } \\
\text { Sistemleri }\end{array}$ & 0,07 & 0,02 & 0,03 & 0,06 & 0,27 & 0,17 & 0,14 & 0,24 & 0,16 & 0,13 & 1,30 & 13,04 \\
\hline $\begin{array}{l}\text { Tren Üzeri Konfor } \\
\text { ve Kolaylık } \\
\text { Sistemleri }\end{array}$ & 0,07 & 0,02 & 0,01 & 0,01 & 0,03 & 0,15 & 0,14 & 0,05 & 0,02 & 0,11 & 0,61 & 6,14 \\
\hline $\begin{array}{l}\text { Tren Üzeri Dijital } \\
\text { Bakım ve Kontrol } \\
\text { Sistemleri }\end{array}$ & 0,04 & 0,02 & 0,01 & 0,01 & 0,01 & 0,02 & 0,10 & 0,03 & 0,09 & 0,06 & 0,37 & 3,75 \\
\hline $\begin{array}{l}\text { Sürücü Kontrol } \\
\text { Sistemleri }\end{array}$ & 0,04 & 0,02 & 0,02 & 0,01 & 0,01 & 0,01 & 0,02 & 0,13 & 0,12 & 0,06 & 0,43 & 4,31 \\
\hline $\begin{array}{l}\text { İstasyon Güvenlik } \\
\text { ve Bilet Sistemleri }\end{array}$ & 0,12 & 0,02 & 0,01 & 0,01 & 0,02 & 0,02 & 0,00 & 0,03 & 0,12 & 0,06 & 0,41 & 4,10 \\
\hline $\begin{array}{l}\text { İstasyon Konfor ve } \\
\text { Kolaylık } \\
\text { Sistemleri }\end{array}$ & 0,04 & 0,02 & 0,01 & 0,01 & 0,03 & 0,00 & 0,00 & 0,00 & 0,02 & 0,11 & 0,25 & 2,45 \\
\hline $\begin{array}{l}\text { İstasyon Peron } \\
\text { Kontrol Sistemleri }\end{array}$ & 0,04 & 0,02 & 0,01 & 0,01 & 0,01 & 0,01 & 0,01 & 0,00 & 0,00 & 0,02 & 0,12 & 1,23 \\
\hline Toplam & 1,00 & 1,00 & 1,00 & 1,00 & 1,00 & 1,00 & 1,00 & 1,00 & 1,00 & 1,00 & 10,00 & 100,00 \\
\hline
\end{tabular}

Yapılan uygulama sonucu elde edilen yüzdelik önem ağırlıkları değerlendirilmiş, sinyalizasyon sistemleri \%26,65 ile en kritik alt sistem olarak tespit edilmiştir. Uygulamada sinyalizasyon sistemlerini önem ağırlı̆̆ 1 olarak \%23,47 ile makas sistemleri takip etmiştir. Önem ağırlıkları değerlendirildiğinde sinyalizasyon ve makas sistemleri önem ağırlı̆̆ının \%50'sini oluşturmuş ve işletmede bulunan güvenlik ve sürdürülebilirliğin sağlanabilmesi en kritik sistemler olarak tespit edilmiştir. Tablo 5' te yüzdesel olarak önem ağırlık özeti verilmiştir.

Tablo 5. Akıllı raylı sistemlerde alt sistem risk anahtar performans göstergeleri önem ağırlık sırası özeti

\begin{tabular}{cc}
\hline Akıllı Raylı Sistemler KPIs & Önem Ağırlıkları (\%) \\
\hline Sinyalizasyon Sistemleri & 26,65 \\
Makas Sistemleri & 23,47 \\
Tren Teşkil ve İkmal Sistemleri & 14,85 \\
ERTMS, CTC ve TMİ Haberleşme Sistemleri & 13,04 \\
Tren Üzeri Konfor ve Kolaylık Sistemleri & 6,14 \\
Tren Üzeri Dijital Bakım ve Kontrol Sistemleri & 3,75 \\
Sürücü Kontrol Sistemleri & 4,31 \\
İstasyon Güvenlik ve Bilet Sistemleri & 4,10 \\
İstasyon İklimlendirme Sistemleri & 2,45 \\
İstasyon Peron Kontrol Sistemleri & 1,23 \\
Toplam & 100,00 \\
\hline
\end{tabular}

Akıllı raylı sistemlerdeki alt sistemler detaylı olarak incelendiğinde tüm bu sistemler kritik ve hayati öneme sahiptirler. Riskler açısından ele alındığında her bir sistem kendi özelinde risk seviyesi bulunmaktadır. Bu çalışmada alt sistemlerin birbirleri arasındaki önem değerlerine uzman görüşü alınarak AHP yöntemi ile hesaplamalar yapılmıştır. Alt sistemler üzerinde yaşanabilecek bir güvenlik zaafiyeti veya personel hataları açısından ele alınan en sık yaşanan ve yaşanabilecek riskler detaylı olarak Tablo 6.' da verilmiştir. 
Tablo 6. Akıllı raylı sistemlerdeki alt sistemler özelinde güvenlik açısından yaşanabilecek muhtemel riskler.

\begin{tabular}{cc}
\hline Demiryolu risk 1 & Çalışma hattında trenin çalışana çarpması veya vakum etsiyle yaralaması \\
Demiryolu risk 2 & Çalışma hattında trenin deray olması veya trenlerin çarpışması \\
Demiryolu risk 3 & Tren teşkil ve ikmalden kaynaklı aksaklıktan dolayı seferin gerçekleşmemesi \\
Demiryolu risk 4 & Bitişik hat üzerinde trenin makine, malzeme ve ekipmanlara çarpması \\
Demiryolu risk 5 & Verilerin korsanlar tarafından çalınması veya satılması \\
Demiryolu risk 6 & Verilerin çalınması sonucu finansal olarak kayıpların olması \\
Demiryolu risk 7 & Verilerin çalınması sonucu kurumun itibarının azalması \\
Demiryolu risk 8 & Personel hataları \\
Demiryolu risk 9 & Çalışanın elektrik çarpmasından etkilenmesi \\
Demiryolu risk 10 & Donanımsal hatalar \\
\hline
\end{tabular}

\section{Sonuç}

Son yıllarda yük ve yolcu bazlı hızla gelişen ve gelişimini sürdürecek olduğu öngörülen raylı sistem teknolojisi, uluslararası normlara uyulması, konforlu ve güvenli seyrin teşkil edilmesi, bakım, onarım ve ortaya çıkabilecek maliyetlerin azaltılması açısından dijitalleşmeye ihtiyaç duymaktadır. Gerçekleştirilen bu dijital dönüşüm ve adaptasyon sistemlerin doğru tanımlanması ve kurgulanması ile birlikte risklerin seviyelendirilip bu riskler üzerinde gerekli akademik ve sektörel bazlı çalışmalara ihtiyaç duymaktadır. Yapmış olduğumuz çalışmada, Analitik Hiyerarşik Süreci (AHP) yöntemi kullanılarak, 5 ayrı uzman görüşü alınmış bu sayede riskler seviyelendirilmiştir. Yapılan analiz sonuçlarına göre, \%26,65 ile sinyalizasyon sistemleri, \%23,47 ile makas sistemleri risk öncelikli başlıklar olarak ortaya çıkmaktadır. Gelişen dijital süreç ve adaptasyonlar sayesinde, siber güvenlik başlığı ilerleyen süreçte önemini artıracağı ön görülmektedir. Yapılacak olan demiryolu adaptasyonu, yeni sistem ve hat kurulumlarında öncelikli olarak seyir güvenliğinin sağlanması ve siber güvenlik açısından dış kaynak müdahale ve saldırılarının önlenmesi öncelikli çalışılması gereken kritik başlıklar olarak tespit edilmiştir.

Sinyalizasyon, makas, sürücü kontrol veya haberleşme sistemlerinde meydana gelebilecek olumsuzluklar çarpışmalara, deray durumlarına sebep olabilmektedir. Tren teşkili veya ikmalle ilgili problemler arızaların ortaya çıkmasını ve seyrin tamamlanamamasına sebep olabilmektedir. Diger kontrol veya konfor sistemlerinde oluşabiliecek olumsuzluklar yolcu veya çalışanların olumsuz bekleme veya seyir süreci geçirmelerine ayrıca işletmeyi maddi bir zararla karşılaştırabilmektedir. Belirlenen kritik başlıklar ile ilgili yapılacak çalışmalar, özellikle sinyalizasyon başlıca olacak şekilde meydana gelen kazaların ve muhtemel oluşabilecek olumsuzlukların önlenmesini sağlayacaktır.

Belirlenen kritik başlıklar ile birlikte kurulan yeni sistemler ve mevcut sistemlerin akıllı ulaşıma adaptasyonu uygun güvenli modeller ile oluşturulması gerekmektedir. Yapılacak çalışmalar oluşturulan bu modeller ile birlikte kurgunun temelde uygun bir biçimde yapılmasını ve bu sayede ileride karşılaşılması muhtemel hatalar ve kazalar ile birlikte sistemsel yetersizliğin ortaya çıkması sonucu maddi kayıpların önlenmesinde kritik bir önem taşıyacaktır. Bu sistemlerin kurulumu ve gelişimi ülkemizde olduğu gibi dünya üzerinde de mevcut eksiklikler ile devam etmekte olup yapılacak çalışmalar sektörel bazlı gelişimlere imkân tanıyacaktır.

\section{Kaynakça}

[1] C. Özarpa, M.A. Aydın, İ. Avc1, "International security standards for critical oil, gas, and electricity infrastructures in smart cities: A survey study," Innovations in Smart Cities Applications Volume 4, Capter 89, Springer, 2021.

[2] Y. Sarıkavak, "Demiryolu endüstrisinde akıllı ulaştırma sistemleri ve Türkiye'deki uygulama örnekleri," Akillı Ulaşım Sistemleri ve Uygulamaları Dergisi, 1 (2) , 22-32, 2018. 
[3] D. Bonde, et al., "Smart raılway system for safe transportatıon," OAIJSE, Volume 3 Special Issue1, 2018.

[4] A. Lamssaggad, N. Benamar, A.S. Hafid, M. Msahlı, "A survey on the current security landscape of intelligent transportation systems," IEEE Access, Volume 9, 2021.

[5] TCDD GENEL MÜDÜRLÜĞÜ, 2020 Y1lı Performans Programı.

[6] Makina Mühendisleri Odası, Ulaşımda Demiryolu Gerçeği, Yayın No: MMO/703, 2019.

[7] Railway Delivery Group National Rail, "Changing track proposals for a more customer focussed, joined-up and accountable railway," 2019.

[8] [. TURASAŞ, "https://www.turasas.gov.tr/turasas-eskisehir-bolge-mudurlugu-ile-lokomotiflerdijitallesiyor",2021.

[9] M. E. Kenanoğlu, M. Aydın, "Akıllı ulaşım sistemlerinin dışsallık bağlamında değerlendirilmesi: seçilmiş ülke uygulamaları,” ÇOMÜ Uluslararası Sosyal Bilimler Dergisi 3 (2), 363-387 , 2018.

[10]S. Özdemir, E. Özcan, "AHP, COPRAS ve tamsayılı programlama entegrasyonu ile demiryolu araçlarında bakım planlaması,"Demiryolu Mühendisliği, no. 12, pp. 1-12, July. 2020. doi: 10.47072/demiryolu.678580.

[11]N. Mohajer1, G.R. Amın, "Railway station site selection using analytical hierarchy process and data envelopment analysis," Computers \& Industrial Engineering, 1(59), 107-114, 2010.

[12]H. Bıyıkçı, "Büyük şehirlerde doğal gaz dağıtımı akıllı şebeke olgunluk seviyesi analizi: İstanbul için durum çalışması," Şehir Üniversitesi Fen Bilimleri Enstitüsü, Yüksek Lisans Tezi, Aralık 2016.

[13]İ. Avcı, "Akıllı doğal gaz şebekelerinde siber güvenlik açıklarının araştırılması ve olgunluk modeli geliştirilmesi,” İstanbul Üniversitesi Cerrahpaşa Lisansüstü Eğitim Enstitüsü, Doktora Tezi, Ocak 2021.

[14] C. Kaya, "Demiryolu hatlarının emniyetinin sağlanması ile ilgili risk analizleri," Sakarya Üniversitesi Fen Bilimleri Enstitüsü, Yüksek Lisans Tezi, Mayıs 2019.

[15]H. Şengün, A. Koçhan, S.G. Meydan Yıldız, "Akıllı kentler ve dijital (Siber) güvenlik," 13. Uluslararası Kamu Yönetimi Sempozyumu, 2019.

[16] M.Z. Gündüz, R. Daş, “Akıllı şebekelerde iletişim altyapısı ve siber güvenlik,” Iğdır Üniversitesi Fen Bilimleri Enstitüsü Dergisi, 10(2): 970-984, 2020.

[17] V. Göçoğlu , "Cyber security of critical infrastructures in smart cities," Uluslararası Yönetim Akademisi Dergisi, 2019.

[18] A. Thaduri, M. Aljumaili, R. Kour, R. Karim , "Cybersecurity for e-Maintenance in railway infrastructure: risks and consequences,” Int J Syst Assur Eng Manag, 10(2):149-159, 2019.

[19] N. Tekteş, M. Tekteş, "Future goals of int elligent transportation systems in the world examination of Japan sample," Paradoks Ekonomi, Sosyoloji ve Politika Dergisi, 2019.

[20]D.A. Hahn, A. Munir, V. Behzadan, "Security and privacy issues in intelligent transportation systems: classification and challenges,” IEEE Intell. Transp. Syst. Mag, 2019.

[21] K.B. Kelarestaghi, M. Foruhandeh, K. Heaslip , "Intelligent transportation system security: Impactoriented risk assessment of in-vehicle networks," IEEE Intelligent Transportatıon Systems Magazine, 2019.

[22] M. Y. Çodur, S. Topdağı, "Akıllı ulaşım sistemlerinin kent içi toplu taşımaya etkisi: Erzurum ili örneği,” Erzincan Üniversitesi Fen Bilimleri Enstitüsü Dergisi, 11(3), 576-586, 2018.

[23]H. Ulvi, F. Akdemir , "Kent içi raylı sistem yatırım ölçütlerinin üzerine bir araştırma: Erzincan kent içi raylı sistem örneği," Uluslararası Bilimsel Araştırmalar Dergisi, Cilt: 4 Sayı: 2 Sayfa: 333-354, 2019.

[24]H. Abdo, M. Kaouk, J.-M. Flaus, F. Masse, "A safety/security risk analysis approach of Industrial Control Systems: A cyber bowtie - combining new version of attack tree with bowtie analysis," Computers \& Security, Volume 72, Pages 175-195, 2018.

[25] S. Karayanık, "Marmaray sinyalizasyon sistemleri," Demiryolu Mühendisliği, sayı. 4, ss. 71-77, Ara. 2016.

[26] M.C. Savaş, T. Kara, "Demiryolu trafiği yönetimi için merkezi olmayan kontrol kistemi," 2. Uluslararası Raylı Sistemler Mühendisliği Sempozyumu (ISERSE’13), 9-11 Ekim 2013.

[27] B. Sarımehmet, M. Hamurcu, and T. Eren, " "Çok kriterli karar verme: Kırıkkale YHT istasyonu - şehir bağlantısının sağlanması,” Demiryolu Mühendisliği, no. 11, pp. 26-40, Jan. 2020..

[28] Saaty, T. L. , "Scaling method for priorities in hierarchical structures.” J. Math. Psychol., 15(3), 234$281,1977$.

[29]H. Ö. Özsoy, "Evaluatıon of personal mobility vehicle concept designs by using analytıcal hierarchy and analytical network processes," İstanbul Ticaret Üniversitesi Sosyal Bilimler Dergisi, Y1l:18 Say1:35 /1 s.125-150, 2019. 
[30] Ö.F. Görçün, "Selectıon of fuel supplıer for transport firms by usıng the ahp," Yönetim ve Ekonomi Araştırmaları Dergisi, Cilt: 18, Mart 2020.

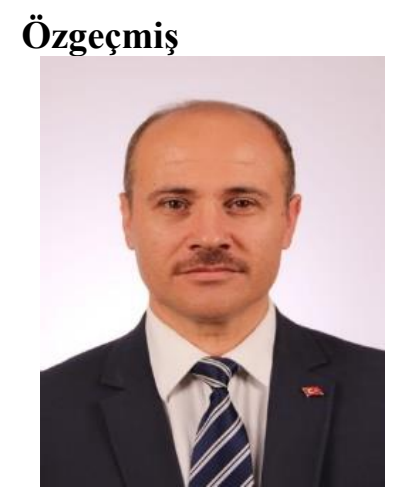

\section{Cevat ÖZARPA}

Karabük Üniversitesi Makine Mühendisliği Bölümünde Doktor Öğretim Üyesi olarak çalışmaktadır. Lisans eğitimini Gaziantep Üniversitesi'nde, Yüksek Lisansını İstanbul Teknik Üniversitesi'nde, Doktorasını Sakarya Üniversitesi'nde Makine Mühendisliği tamamladı. Doktora sonrası çalışmalarını ABD'de Virginia Commonwealth Üniversitesi Makine Mühendisliği Tasarım Üretim Laboratuvarı'nda tamamladı. Çalışma alanları arasında; Akıllı şebekeler, SCADA ve siber güvenlik, Doğalgaz, kaynak teknolojileri, korozyon, OHSAS, Varlık yönetimi, otonom araçlar bulunmaktadır. İstanbul Teknik Üniversitesinde Çevre Mühendisliği dersleri vermiştir. Evli ve 5 çocuk babasıdır.

E-Posta: cevatözarpa@karabuk.edu.tr

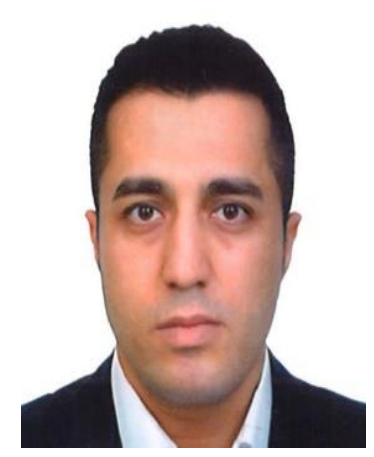

\section{İsa AVCI}

Karabük Üniversitesi Bilgisayar Mühendisliği Bölümünde Doktor Öğretim Üyesi olarak çalışmaktadır. İstanbul Üniversitesi Cerrahpaşa'da doktora eğitimini tamamlamıştır. İGDAŞ, THY gibi farklı kurumlarda proje yöneticisi olarak çalışmıştır. Çalışma alanları arasında, proje yönetimi, iş analizi, SCADA sistemleri, akıllı doğal gaz a ̆ sistemleri, akıllı şehirler, yapay zeka, makine öğrenmesi, yapay sinir ağları, derin öğrenme, siber güvenlik, yama yönetimi, AHP yöntemi, siber riskler ve tehditler, kritik altyapılar ve EKS sistemleridir. Evli ve 3 çocuk babasıdır.

E-Posta: isaavci@karabuk.edu.tr

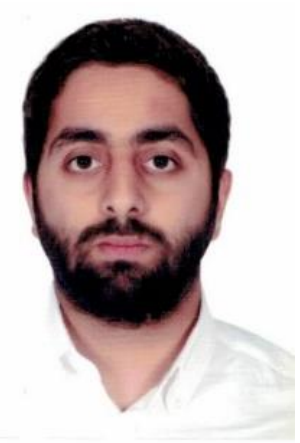

\section{Bahadır Furkan KINACI}

Karabük Üniversitesi Raylı Sistemler bölümünde Öğretim Görevlisi olarak çalışmaktadır. Lisans eğitimini Karabük Üniversitesi Raylı Sistemler Mühendisliği bölümünde Yüksek Lisans eğitimini Sivas Cumhuriyet Üniversitesi Makine Mühendisliği bölümünde tamamlamıştır. Özel sektörde proje yöneticisi olarak çalışmıştır. Çalışma alanları arasında, proje yönetimi, akıllı şebekeler, akı1lı ulaşım, AHP yönetimi, SCADA sistemleri, ulaşım sistemleri, kaynak teknolojileri, mekanik tasarım ve analiz bulunmaktadır.

E-Posta: furkankinaci@karabuk.edu.tr

\section{Beyanlar:}

Bu makalede bilimsel araştırma ve yayın etiğine uyulmuştur.

Tüm yazarların eşit oranda katkısı olmuştur. 